\title{
The Mitroflow aortic valve: A past, present, and future illuminated
}

\author{
Leora B. Balsam, MD, ${ }^{\mathrm{a}}$ and Abe DeAnda, Jr, $\mathrm{MD}^{\mathrm{b}}$
}

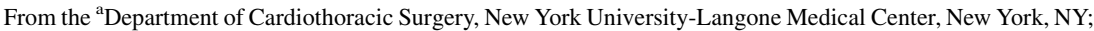
and ${ }^{\mathrm{b}}$ Division of Cardiothoracic Surgery, University of Texas Medical Branch-Galveston, Galveston, Tex Disclosures: Authors have nothing to disclose with regard to commercial support.

Received for publication Oct 11, 2016; accepted for publication Oct 12, 2016.

Address for reprints: Leora B. Balsam, MD, Department of Cardiothoracic Surgery, NYU-Langone Medical Center, 530 First Ave Suite 9V, New York, NY 10016 (E-mail: leora.balsam@nyumc.org).

J Thorac Cardiovasc Surg 2017;153:40-2

$0022-5223 / \$ 36.00$

Copyright (C) 2016 by The American Association for Thoracic Surgery

http://dx.doi.org/10.1016/j.jtcvs.2016.10.034
}

The Mitroflow aortic valve (Sorin Group USA Inc, Arvada, Colo) is back in the spotlight in this issue of the Journal. The Mitroflow valve is a bioprosthesis whose unique design features a single sheet of bovine pericardium mounted externally on an acetyl homopolymer stent. ${ }^{1}$ This unusual form, with leaflet mounting outside the stent frame, translates into larger effective orifice areas for a given diameter when compared with most other commercially available porcine and pericardial valves. A pericardial valve with a similar footprint was recently introduced by St Jude Medical (Trifecta; St Jude Medical Inc, Saint Paul, Minn). The favorable hemodynamics of the Mitroflow valve have made it an attractive option for the small aortic annulus, either in lieu or in combination with root-enlarging procedures.

The Mitroflow valve was first introduced into the European market in 1982 and was approved for use in the US market in 2007. Over the years, the valve has undergone numerous manufacturing and design changes that address failure modes identified in clinical practice. ${ }^{1}$ With the first-generation model (Mitroflow 11), leaflet tears occurred as the result of abrasion against the ribbed polyester-covered frame, resulting in valvular insufficiency. This design flaw was corrected by reversing the polyester so that the smooth side faced the pericardium (second-generation model, 12A, introduced in 1991). The third-generation model (Mitroflow LXA) incorporated minor changes to improve manufacturing efficiency, such as automatic machine sewing and leaflet prefixation with glutaraldehyde (rather than postfixation) to facilitate tissue application on the stent. A fourthgeneration model with phospholipid reduction therapy (Mitroflow PRT) received the European CE mark in 2011 and US Food and Drug Administration approval in 2014.

The Mitroflow valve has been implanted widely (>100,000 implants in patients worldwide), and postapproval data regarding its durability have been varied. With later-generation models (12A and LXA), the primary some studies. 3,4

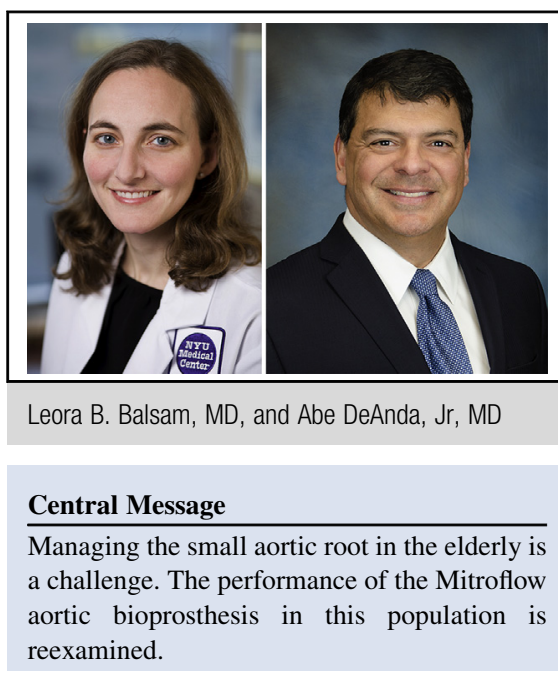

See Article page 31.

mechanism for structural valve degeneration (SVD) is leaflet stiffening and calcification, leading to valvular stenosis over time. A variety of host-specific factors have been shown to contribute to calcific SVD in bioprostheses, including age, renal disease, diabetes, and dyslipidemia. Valve-specific factors, such as antimineralization treatment and valve size, also are likely important. For example, in a rat model, Cunanan and colleauges ${ }^{2}$ demonstrated that subcutaneous implants of pericardial tissue from Mitroflow valves versus Carpentier-Edwards Perimount valves (Edwards Lifesciences, Irvine, Calif) contained 200 times the tissue calcium concentration after 90 days. Cunanan and colleagues attributed this difference to lack of anticalcification treatment of the Mitroflow pericardial leaflet during tissue preparation and fixation. The presence of severe patient-prosthesis mismatch also has been linked to SVD in

Initial reports suggested favorable mid- and late-term outcomes with the Mitroflow valve when compared with other pericardial and porcine bioprostheses. 5,6 More recently, there has been growing focus on the timeline to developing SVD, and some investigators have reported early SVD not only in young patients receiving the Mitroflow valve but also in older patients. ${ }^{4,7}$ A study by Saleeb and colleagues ${ }^{8}$ in children and young adults aged less than 30 years showed rapid development of lifethreatening prosthetic aortic stenosis at 1.5 to 3 years after Mitroflow LXA implantation in 5 of 15 patients; in contrast, 
no valve failures were noted in 12 patients with CarpentierEdwards Perimount Magna and Magna Ease valves at 3 years. ${ }^{8}$ The American College of Cardiology/American Heart Association Guidelines specifically state that tissue valves should be used for patients aged more than 70 years because of the risk of early SVD in younger patients, with exceptions made for patient choice and inability to take lifelong anticoagulation. ${ }^{9}$ That said, the performance of the Mitroflow valve in the series of young patients by Saleeb and colleauges $^{8}$ was particularly poor and may relate to the absence of anticalcification treatment of the Mitroflow LXA valve. Saleeb and colleagues concluded that "this aortic bioprosthesis should not be implanted in the young." 8 The follow-up question of course is should the valve be implanted in the old? This has led to a flurry of articles evaluating the mid- and late-term outcomes of the Mitroflow valve in the elderly, including the study by De Paulis and colleagues $^{10}$ in this issue of the Journal. Some have suggested that a form of accelerated SVD exists in elderly patients receiving the Mitroflow valve, ${ }^{4,7}$ and others suggest that the process is more gradual.

In this issue of the Journal, De Paulis and colleagues ${ }^{10}$ report their experience with implantation of small Mitroflow valves (19- and 21-mm diameters, models $12 \mathrm{~A}$ and LXA) in an elderly population. They describe a surgical bias toward implanting these valves in older patients with small annuli to maximize hemodynamic benefit with a small prosthesis while avoiding the risk of root enlargement in the elderly. Between the years of 2005 and 2011, 205 implants were performed in an Italian patient population with a mean age of 76 years. Of these, approximately half were $19-\mathrm{mm}$ implants and the remainder were $21-\mathrm{mm}$ implants. Severe patient-prosthesis mismatch on postdischarge echocardiogram was infrequent $(10.7 \%$ in the $19-\mathrm{mm}$ cohort and $0 \%$ in the 21 -mm cohort). SVD was defined by echocardiographic criteria, and mean echocardiography follow-up was 5 years. Mortality, reoperation, and SVD did not differ between the recipients of $19-\mathrm{mm}$ versus 21-mm valves. Cumulative freedom from SVD at 5 and 9 years was $94.8 \% \pm 1.6 \%$ and $77.4 \% \pm 5.4 \%$, respectively. De Paulis and colleagues ${ }^{10}$ conclude that the time course of SVD after Mitroflow implantation is worrisome even in patients aged more than 70 years, and they state that on the basis of this experience, they have discontinued use of the product. Have they begun performing more root enlargements or chosen a different bioprosthesis? The reader is left to wonder, but perhaps a reasonable followup study would be to compare the outcomes with Mitroflow with their concurrent experience with 430 CarpentierEdwards Perimount and Magna Ease 19-mm and 21-mm implants.

For the practicing surgeon, navigating the valve prosthesis literature can be challenging, especially considering the sheer volume of studies. Most mid- and long-term studies are retrospective and reflect single-center experiences. At times, 1 valve is compared with another, and at other times (as in the study by De Paulis and colleagues ${ }^{10}$ ), results with only 1 valve are reported. As the adage goes, you can't compare apples to oranges, but a clear benchmark is an important starting point. Inferences and historical controls incompletely tell the story. Understandably, the goal is to identify a durable bioprosthesis that minimizes the need for reintervention for SVD, but the question remains, is the Mitroflow experience any worse in the elderly than other bioprostheses? The problem is further compounded by the fact that different definitions of SVD have been used in the literature, ranging from echocardiographic to pathologic ones. Although De Paulis and colleagues ${ }^{10}$ use the consensus definition, the actual burden of SVD likely falls somewhere in between, because echocardiographic criteria likely overdiagnose it and pathologic criteria clearly underdiagnose it (particularly in the elderly, who are unlikely to undergo reoperation and valve explantation). Last, when judging a prosthesis on the basis of echocardiographic progression of SVD, one must consider the clinical significance, particularly in the context of age.

Moving forward, how should we handle the small aortic root in the elderly? Should the Mitroflow valve be supplanted? With its reincarnation in the new PRT model, will the slate be drawn clean for the Mitroflow prosthesis? Not surprisingly, we are left with more questions than are answered and opportunities to better this field with stronger science.

\section{References}

1. Jamieson WRE, Yankah CA, Lorusso R, Benhameid O, Hayden RI, Forgie R, et al. Clinical and hemodynamic performance of the Sorin Mitroflow pericardia bioprosthesis. In: Chen Y-F, Luo C-Y, eds. Aortic valve. Rijeka, Croatia: InTech, 2001. Available at: http://www.intechopen.com/books/aortic-valve/clinical-andhemodynamic-performance-of-the-sorin-mitroflow-pericardial-bioprosthesis. Accessed October 6, 2016

2. Cunanan CM, Cabiling CM, Dinh TT, Sheh SH, Tran-Hata P, Rutledge JH III, et al. Tissue characterization and calcification potential of commercial bioprosthetic heart valves. Ann Thorac Surg. 2001;71:S417-21.

3. Piccardo A, Blossier JD, Le Guyader A, Orsel I, Sekkal S, Cornu E, et al. Fate of aortic bioprostheses: an 18-year experience. J Thorac Cardiovasc Surg. 2016; 151:754-61.e1.

4. Senage T, Le Tourneau T, Foucher Y, Pattier S, Cueff C, Michel M, et al. Early structural valve deterioration of Mitroflow aortic bioprosthesis: mode, incidence, and impact on outcome in a large cohort of patients. Circulation. 2014;130: 2012-20.

5. ISTHMUS Investigators. The Italian study on the Mitroflow postoperative results (ISTHMUS): a 20-year, multicentre evaluation of Mitroflow pericardial bioprosthesis. Eur J Cardiothorac Surg. 2011;39:18-26.

6. Yankah CA, Pasic M, Musci M, Stein J, Detschades C, Siniawski H, et al. Aortic valve replacement with the Mitroflow pericardial bioprosthesis: durability results up to 21 years. J Thorac Cardiovasc Surg. 2008;136:688-96.

7. Alvarez JR, Sierra J, Vega M, Adrio B, Martinez-Comendador J, Gude F, et al. Early calcification of the aortic Mitroflow pericardial bioprosthesis in the elderly Int Cardiovasc Thorac Surg. 2009;9:842-6.

8. Saleeb SF, Newburger JW, Geva T, Baird CW, Gauvreau K, Padera RF, et al. Accelerated degeneration of a bovine pericardial 
bioprosthetic aortic valve in children and young adults. Circulation. 2014; 130:51-60.

9. Nishimura RA, Otto CM, Bonow RO, Carabello BA, Erwin JP III, Guyton RA, et al. 2014 AHA/ACC guideline for the management of patients with valvular heart disease: executive summary: a report of the American College of Cardiol-
ogy/American Heart Association Task Force on Practice Guidelines. J Am Coll Cardiol. 2014;63:2438-88.

10. De Paulis R, D'Aleo S, Bellisario A, Salica A, Weltert L, Scaffa R, et al. The fate of small size Mitroflow valve prostheses in an old population. J Thorac Cardiovasc Surg. 2017;153:31-9. 